\title{
CENOURAS MINIMAMENTE PROCESSADAS EM EMBALAGENS COM ATMOSFERAS MODIFICADAS E TRATADAS COM RADIAÇÃO GAMA: AVALIAÇÃo MICROBIOLÓGICA, FÍSICO-gUÍMICA E QUÍMICA ${ }^{1}$
}

\author{
Keila S. Cople LIMA ${ }^{2, *}$, Antonio L. S. LIMA ${ }^{3}$, Rosa H. LUCHESE ${ }^{4}$, \\ Ronoel L. O. GODOY 5 , Armando U. O. SABAA-SRUR ${ }^{6}$
}

\begin{abstract}
RESUMO
As cenouras são as principais fontes de origem vegetal em carotenóides provitamínicos A ( $\alpha$ e o $\beta$-caroteno) e podem ser transformados em vitamina A dentro do organismo animal. Segundo a Pesquisa de Orçamento Familiar realizada na região Sudeste do Brasil, no grupo de raízes e tubérculos, a cenoura é amplamente consumida. As cenouras minimamente processadas foram acondicionadas em embalagens com atmosferas modificadas de $5 \% \mathrm{O}_{21} 10 \% \mathrm{CO}_{2}$ e $21 \% \mathrm{O}_{2}$ (ar sintético), e tratadas com radiação ionizante gama, fonte de césio, nas doses de $0,25,0,50,0,75$ e $1,00 \mathrm{kGy}$. Os produtos após o emprego da radiação foram armazenados em refrigeração de $5^{\circ} \mathrm{C}$ durante 24 dias. Os diferentes tratamentos da cenoura e o grupo controle foram avaliados através das análises de pH, sólidos solúveis totais (SST), acidez total titulável (ATT) e microbiologia. Os resultados de microbiologia evidenciaram que os produtos tratados com as doses de 0,50 , 0,75 e 1,0kGy apresentaram redução de 3 a 4 ciclos logarítmicos na contagem total de mesófilos (CTM) logo após a irradiação e uma vidaútil de 20 dias. Não foram detectados coliformes totais e E. coli até o 24 dia. Os patógenos B. cereus, Salmonellae Estafilococos coagulase positivos em $0,1 \mathrm{~g}$ do produto, também não foram detectados. As contagens de bactérias láticas mantiveram-se menores que $100 \mathrm{UFC} / \mathrm{g}$. O processo de irradiação em baixas doses mostra-se promissor na manutenção da qualidade e apresenta-se como uma medida alternativa na redução de perdas pós-colheita.

Palavras-chave: cenoura; irradiação; minimamente processada e microbiologia.
\end{abstract}

\section{SUMMARY}

MINIMALLY PROCESSED CARROTS IN MODIFIED ATMOSPHERE PACKAGING AND GAMA IRRADIATION TREATMENT: MICROBIOLOGICAL, FISICAL-CHEMISTRY AND CHEMISTRY EVALUATION. Carrots are the mains vegetable sources of carotenoids provitamin A ( $\alpha$ and $\beta$-carotene) which might be transformed into vitamin A in animal organism. According to the Family Budget Survey (FBS, 1991) carried out in the Brazilian Southeast, within the roots and tubers group, carrots are widely consumed. The minimally processed carrots were packaging with $5 \% \mathrm{O}_{2} / 10 \% \mathrm{CO}_{2}$ and $21 \% \mathrm{O}_{2}$ (sintetic air), and $\gamma$ ionizing radiation treatments was carried out with a ${ }^{137} \mathrm{Cs}$ source, of $0.25,0.50,0.75$ and $1.0 \mathrm{kGy}$ doses. After radiation treatments, the products were stored at $5^{\circ} \mathrm{C}$ for 24 days. The different treatments and the control group were evaluated by analysing for $\mathrm{pH}$, total soluble solids (TSS), total titratable acidity (TTA) and microbiologycal. It was made clear by the microbiologycal analysis results that the products treated with $0.5,0.75$ and $1.0 \mathrm{kGy}$ presented a decrease of 3 to 4 logaritmic cicles in aerobic mesophilic microflora just after irradiation and shelf life of 20 days. Total coliforms and $E$. coliwere not detected until the $24^{\text {th }}$ day. The B. cereus, Salmonella and Stafilococos coagulase positive were also not detected in $0.1 \mathrm{~g}$ of product. The latic microflora were always below detection $100 \mathrm{CFU} / \mathrm{g}$ level. The results show that the low dose irradiation process is very promising to maintain the quality of the product, being a good alternative to avoid post harvest losses.

Keywords: carrot; irradiation; minimally processed and microbiology.

\section{1 - INTRODUÇÃo}

A matéria-prima utilizada nesta pesquisa foi a cenoura (Daucus carota L.) cultivar Nantes. Segundo a PESQUISA DE ORÇAMENTO FAMILIAR [31] realizada na região Sudeste do Brasil, no grupo de raizes e tubérculos, a cenoura é amplamente consumida. Pertence a familia das umbeliferas, que produz raízes aromáticas e comestiveis, caracterizando-se como uma das mais importantes olericulturas, em função do consumo em todo mundo, pela extensão de área plantada e pelo grande envolvimento sócio-econômico dos produtores rurais.

\footnotetext{
Recebido para publicação em 21/02/2002. Aceito para publicação em 19/11/2002 (000803).

2. Faculdades Integradas Bennett. Av. Mal. Fontenelle, 4784, casa 06, Mag. Bastos, Rio de Janeiro, RJ, CEP 21750-550,keilacople@ig.com.br. 3. Instituto de Projetos Especiais, Centro Tecnológico do Exército. 4. Departamento de Ciência e Tecnologia de Alimentos UFRRJ.

5. EMBRAPA Agroindústria de Alimentos, Guaratiba, Rio de Janeiro. DNBE, Instituto de Nutrição da UFRJ.

* A quem a correspondência deve ser enviada.
}

É uma das hortaliças mais cultivadas no Brasil, apresentando a maior produção no período de julho a novembro, preferindo climas amenos, conforme a variedade. A variedade Nantes é adaptada ao plantio de inverno, que compreende o período de março a junho, desenvolvendo-se bem nas temperaturas entre 8 a $22^{\circ} \mathrm{C}$, com a colheita ocorrendo em 70 a 120 dias. Apresentam folhagem verde-escura, com 25-30 centímetros de altura, raizes axiais tuberosas, do tipo cilindrica, lisa, média de 16 centímetros de comprimento e 3 centímetros de diâmetro, com coloração laranja-avermelhada [30].

Métodos convencionais de conservação como tratamentos pelo emprego do calor, do frio e controle de umidade, proporcionam uma completa inativação enzimática e microbiológica, além de prolongarem consideravelmente a vida-útil dos produtos [4, 13]. Entretanto, novas tecnologias estão sendo desenvolvidas no processamento dos alimentos devido a nova tendência de consumo da vida moderna, por alimentos mais nutritivos, atrativos, convenientes e prontos para o consumo $[28,41]$. 
Tecnologias novas como os produtos minimamente processados, acondicionados em embalagens com atmosferas modificadas ou controladas, armazenados com controle de umidade e refrigeração, são métodos de conservação que visam manter o frescor e o estado natural dos produtos, contudo, aumentam modestamente a vida-útil dos produtos. Apesar do aumento da demanda mundial por hortaliças e frutas minimamente processadas e prontas para o consumo, uma maior expansão nesse segmento de produtos, tanto para o mercado interno, como para o mercado externo tem sido dificultada pela curta vida-útil desses produtos [13,32].

As hortaliças e frutos minimamente processados se caracterizam por um preparo minimo como pesagem, seleção, higienização, descascamento e corte. Embora o estado fresco dos vegetais e o valor nutritivo sejam semelhantes ao alimento natural, apresentam aumento na taxa de respiração e a possibilidade de haver contaminação por microrganismos, existindo necessidade de prevenção e controle durante todo o manuseio, incluindo o processo de fabricação e acondicionamento dos produtos [33].

Para prolongar a vida-útil dos vegetais processados, outros métodos e técnicas estão sendo utilizados, como: a refrigeração, que reduz a taxa de respiração e senescência; o controle da umidade relativa, que minimiza a perda de água pelos produtos; embalagens com atmosfera modificada ou controlada, que também diminui a taxa de respiração e a senescência; aditivos químicos, para controlar alterações fisiológicas e reduzir a carga microbiana [35]; e o emprego da irradiação ionizante, tem mostrado um potencial efeito como tecnologia auxiliar na redução de perdas pós-colheita, manutenção da qualidade nutricional e efetiva na redução da população microbiana de produtos hortifrutícolas [14, 18, 20, 23].

O emprego do processo de irradiação em alimentos já foi aprovado por 34 países em mais de 40 variedades de alimentos para desinfestação de grãos de cereais; controle de microrganismos patogênicos e prolongamento da vida-útil em carnes, frutas, hortaliças, raizes e tubérculos; desinfestação, retardar a maturação e eliminação de moscas das frutas; inibição de brotamento em tubérculos e bulbos, entre outros efeitos [6, 27].

As fontes de radiações ionizantes autorizadas pela Comissão Nacional de Energia Nuclear para utilização nos estudos de irradiação de alimentos são: os isótopos radioativos emissores de raios gama, a partir do cobalto60 e césio-137; os raios X gerados por máquinas que trabalham com energias de até $5 \mathrm{MeV}$; e os elétrons acelerados gerados por máquinas que trabalham com energias de até $10 \mathrm{MeV}[11,20,29]$.

O presente trabalho teve por objetivo avaliar o efeito da aplicação do processo de radiação $\gamma$ e da refrigeração na extensão da vida-útil de cenouras minimamente processadas, acondicionadas em embalagens herméticas com atmosferas modificadas e armazenadas sob refrigeração a $5^{\circ} \mathrm{C}$, através das avaliações microbiológicas, fisico-quimicas e químicas.

\section{2 - MATERIAIS E MÉTODOS}

\section{1 - Matéria-prima}

Cenouras (Daucus carota, L.) cv. Nantes, oriundas do municipio de São Gotardo - MG, cultivada sob irrigação, em uma região onde há predomínio de solos planos e mecanizados, foram adquiridas no estádio de maturação ótimo para o consumo, ou seja, com as suas caracteristicas sensoriais e nutricionais totalmente desenvolvidas, por tratar-se de uma hortifrutícola não climatérica, e acondicionadas em caixas de madeira tipo $\mathrm{K}$.

A colheita foi realizada no mês de julho de 2001 e imediatamente transportada para a Planta Piloto de Fisiologia e Tecnologia Pós-colheita da EMBRAPA Agroindústria de Alimentos, em Guaratiba, Rio de Janeiro. Em seguida houve pesagem, pré-seleção, pré-lavagem em água corrente, seleção, classificação e acondicionamento em "containers" sanitizados.

\section{2 - Elaboração dos produtos}

O fluxograma do processamento, desde a recepção da matéria-prima até a elaboração dos produtos finais, encontra-se na Figura 1. Na Planta Piloto de Fisiologia e Tecnologia Pós-Colheita, as raizes foram removidas das embalagens de remessa, submetidas a pesagem e depois realizado uma pré-seleção, removendo-se aquelas de coloração indesejável e impróprias para o consumo. As raizes foram então lavadas em água corrente, novamente selecionadas para retirada das danificadas fisicamente e com alterações de cor e textura, e classificadas por tamanho com a finalidade de proporcionar uniformidade durante as subseqüentes operações unitárias. Obteve-se um rendimento de $70 \%$ em relação a massa inicial das raizes, sendo posteriormente acondicionadas em "containers" sanitizados, com 200mg/L de cloro.

Durante a operação de descascamento manual, em água corrente, com auxílio de utensílios cortantes afiados e desinfectados, foram eliminadas também as partes que apresentavam as extremidades esverdeadas. Em seguida as raizes foram submetidas ao processo de corte, formato "palha", em um multiprocessador, ROBOT Coupe CL 50. Em operação continua, as cenouras cortadas caíam por gravidade dentro do tanque de imersão com água clorada e refrigerada a $3-5^{\circ} \mathrm{C}$, mantida através de um sistema de refrigeração e trocadores de calor, cuja a temperatura era monitorada por termopares.

As raizes cortadas em tirinhas ou "palha" foram imersas em água clorada na proporção de 5-10 litros por $1 \mathrm{~kg}$ de cenouras, contendo $150 \mathrm{mg} / \mathrm{L}$ de cloro residual livre, oriundo do hipoclorito de sódio comercial, STRATUS, (10-12\% de pureza). A temperatura da água de lavagem foi mantida em refrigeração na faixa de $3-5^{\circ} \mathrm{C}$. O pH da água clorada foi corrigido para 6 com o auxílio de ácido clorídrico comercial, sendo periodicamente monitorado com um medidor manual de $\mathrm{pH}$ Stick da HBI.

A operação de imersão na solução de lavagem e desinfecção foi realizada por 30 minutos e o residual de 
cloro livre foi mensurado pelo teste colorimétrico da MERCK $[34,40]$. Em seguida, as raizes foram enxaguadas com água clorada contendo $10 \mathrm{mg} / \mathrm{L}$ de cloro residual livre.

As cenouras, após o corte, lavagem e desinfecção, foram transferidas para a centrifuga ANGELO PO-Centril, modelo LCV (IPX5 CI.1), para remoção parcial da água, durante 2 minutos com rotação entre 590 a 750 ciclos/ segundo [16].

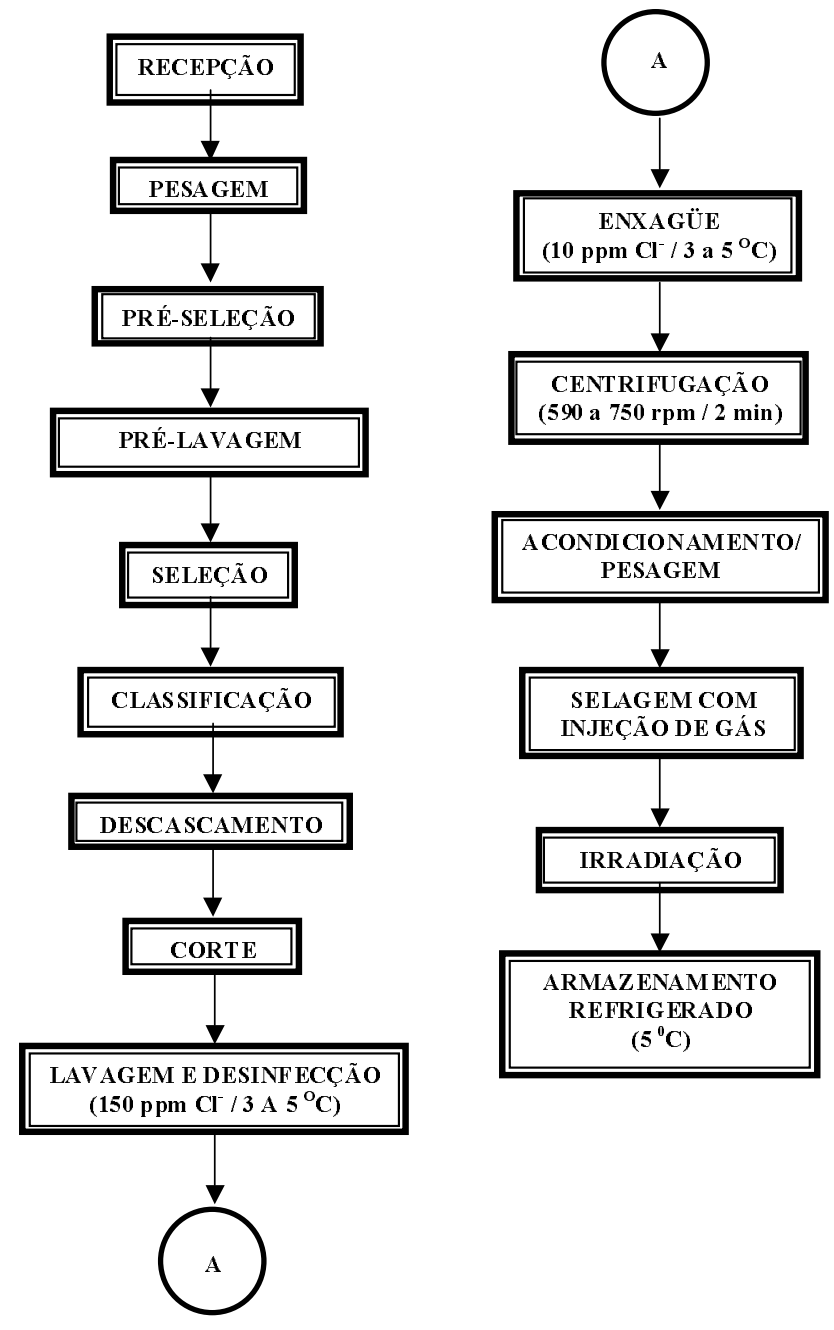

FIGURA 1. Fluxograma das operações unitárias empregadas na elaboração das cenouras minimamente processadas e irradiadas.

Já centrifugadas, foram pesadas e acondicionadas cerca de $120 \mathrm{~g}$ do produto em embalagens plásticas de composição bi-laminar de polietileno de baixa densidade (PEBD) e polipropileno bi-orientado (BOPP), sendo a permeabilidade para o vapor de água de 6-17,5 [g água/( $\mathrm{m}^{2}$.dia) 38oC/90\% umidade relativa], ao oxigênio de $1680-2000\left[\left(\mathrm{~cm}^{3} / \mathrm{m}^{2}\right.\right.$.dia) $25^{\circ} \mathrm{C} /$ a seco] e com espessura de $25 \mu \mathrm{m}$. Foi realizado primeiramente um vácuo parcial com posterior injeção de gases com atmosferas modificadas (AM), sendo em seguida seladas termi- camente na seladora a vácuo Tec Maq AP-450. Os gases que ocupavam o espaço livre (40\% do volume disponivel) das embalagens possuiam a seguinte composição:

- $5 \%$ de $\mathrm{O}_{2}, 10 \% \mathrm{CO}_{2}$, balanço em $\mathrm{N}_{2}$ e ausência de vapor de água [19];

- Ar sintético super-seco.

As cenouras minimamente processadas e acondicionadas em embalagens plásticas seladas individualmente foram colocadas em caixas de isopor, contendo gelo potável e picado, e transportadas, por automóvel, distância de aproximadamente 1500 metros, para o Laboratório do Instituto de Projetos Especiais (IPE) do Centro Tecnológico do Exército (CTEx), em Guaratiba, Rio de Janeiro, para a aplicação da radiação $\gamma$. As doses empregadas nas cenouras minimamente processadas foram de 0,25, 0,50, 0,75 e 1,00kGy, atendendo a dose máxima recomendada pela FDA [12].

O IPE possui um irradiador de pesquisa (IGIPE) com fonte de ${ }^{137} \mathrm{Cs}$ capaz de prover simultaneamente a duas câmaras com volume total de 80 litros. A taxa de dose máxima é igual a $2 \mathrm{kGy} / \mathrm{h}$, tendo boa uniformidade. A razão entre dose máxima e mínima é inferior a $20 \%$. O irradiador é do tipo cavidade com fonte de césio 137 autorecolhivel, controlada por um sistema eletro-eletrônico, com portas blindadas móveis. As câmaras têm dimensões de $138 \times 37 \times 19 \mathrm{~cm}$ cada, sendo uma localizada acima e outra abaixo do plano da fonte. O peso total de sua estrutura é de 19 toneladas. O IGIPE possui ainda vários sistemas de segurança, os quais incluem dispositivos lógicos e travas fixas, que garantem o funcionamento seguro, eliminando qualquer possibilidade de exposição acidental à fonte.

Em seguida as amostras foram armazenadas em estufas refrigeradas com controle de temperatura $\left(5^{\circ} \mathrm{C}\right)$ e umidade $(80-85 \%)$, abrigadas da luz, por 24 dias. Os tratamentos empregados e as respectivas atmosferas modificadas das embalagens foram codificados no trabalho da seguinte forma: as três primeiras letras indicam cenouras minimamente processadas (CMP), os números que se seguem mostram as atmosferas empregadas no interior das embalagens, quantificadas pela presença de oxigênio (5 ou $21 \%$ ) e, finalmente, letras de A a $E$, sendo a letra A para os produtos controles e as letras B, C, D e E para as doses de radiação gama utilizadas, em ordem crescente de energia. Pode-se citar como exemplo o produto CMP5E, cenoura minimamente processa$\mathrm{da}$, irradiada com a dose de $1,00 \mathrm{kGy}$ e acondicionada com atmosfera de $5 \%$ de $\mathrm{O}_{2} / 10 \% \mathrm{CO}_{2}$.

\section{3 - Análises}

Após os tratamentos, as cenouras foram avaliadas através dos seguintes parâmetros: - Sólidos Solúveis Totais (SST) determinados, em triplicata, no tempo zero e a cada 4 dias até completar 20 dias de armazenamento, por leitura direta em refratômetro (PZO modelo RR1), corrigido em relação à temperatura e ácido cítrico contido na amostra, com resultados expressos em ${ }^{\circ}$ Brix [17]; - Acidez Total Titulável (ATT) determinada, em 
triplicata, no tempo zero e a cada 4 dias até completar 20 dias de armazenamento, por titulometria, segundo normas do I.A.L. [17], com resultados expressos em \% de ácido cítrico; - $\mathbf{p H}$ determinado, em triplicata, no tempo zero e a cada 4 dias até completar 20 dias de armazenamento, diretamente em pH-metro [17]; - Avaliação Microbiológica: As amostras foram armazenada na estufa de $\mathrm{BOD}$ a $5^{\circ} \mathrm{C}$, com umidade relativa de $80-85 \%$ durante 24 dias. As análises microbiológicas foram realizadas no tempo zero e a cada 4 dias até completar os 24 dias de armazenamento, através das determinações de Coliformes Totais, Escherichia coli, Salmonella spp, Contagem Total de Mesófilos e a cada 8 dias para Staphilococus aureus, Bacillus cereus e Bactérias Lácticas. As determinações microbiológicas foram precedidas de diluições decimais, exceção para Salmonella spp. Foram utilizados 25 gramas de cada produto e homogeneizados com 225mL no homogeneizador Stomacher (Seward, GB), sendo realizadas diluições subseqüentes, quando necessário. Contagem Total de Aeróbios Facultativos Mesófilos (CTM) - Empregou-se o Agar Contagem (PCA, Oxoid) com semeadura em profundidade de aliquotas de $1 \mathrm{~mL}$, semeaduras seriadas, sendo preparadas duplicatas de cada diluição. As placas foram incubadas a $30^{\circ} \mathrm{C}$ por 48 horas. Coliformes totais e Escherichia coli Seguiu-se a técnica do número mais provável (NMP), recomendada por TATCHER \& CLARCK [38]. Aliquotas de 3 diluições sucessivas foram semeadas em caldo Fluorocult LMX (Merck Darmstadt) e incubados a $37^{\circ} \mathrm{C}$ por 36 a 48 horas, após o período de incubação, os tubos que apresentaram coloração azul esverdeada foram considerados positivos para Coliformes Totais. Os tubos que fluoresceram quando expostos a luz ultravioleta (366nm) foram considerados positivos para a presença de E. coli, confirmada pelo teste do Indol, utilizando-se o reagente de Kovacs. Determinação de Estafilococos coagulase positivos - Seguiu-se a metodologia descrita na ISO/DIS6888-2 [15], empregando-se semeadura de superficie em agar Baird-Parker com incubação a $36^{\circ} \mathrm{C}$ por 24 a 48 horas. As colônias típicas com caracteristicas negras, brilhantes e com halo opaco, decorrente da ação da lecitinase, ou halo claro decorrente da lipase sobre a gema de ovo, e as atipicas foram contadas e confirmadas pelos testes da coloração de Gram, catalase, coagulase e Dnase. Contagem de Bactérias lácticas Utilizou-se o Ágar MRS (Oxoid) com inoculação em superficie e colocação de uma sobre-camada do mesmo meio. As colônias foram contadas após incubação a $30^{\circ} \mathrm{C}$ por 48-72 horas. Contagem de Bacillus cereus - Nesta determinação utilizou-se Agar gema de ovo polimixina manitol azul de bromotimol (Oxoid). Colônias presuntivas de $B$. cereus foram confirmadas pelos testes de catalase, hidrólise da gelatina, redução de nitrato e fermentação de manitol ou xilose. Contagem de Salmonella - Na pesquisa de Salmonella spp em $25 \mathrm{~g}$ do produto, utilizouse a técnica ISO 6579 de 1993 [15]. Esta determinação inclui uma etapa de ressuscitação em água peptonada tamponada, seguida de etapa de enriquecimento seletivo em caldo selenito cistina e caldo Rappaport-Vassiliadis (MERCK) e posterior plaqueamento seletivo nos meios verde brilhante vermelho de fenol (BPLS) e agar xilose, lactose desoxycolato (XLD). Seguem as etapas de confirmação das colônias suspeitas em inoculação nos meios agar ferro três açúcares (TSI) e lisina ferro (LIA), hidrólise da uréia e sorologia.

Os resultados obtidos foram submetidos à análise de variância (tratamento estatístico F de Fischer), com interações múltiplas, no software STATISTICA 99 edition, utilizando-se o nivel de 5\% de significância. Empregouse o Teste de Tukey para identificar as médias que diferiram dos resultados do tempo zero acima do nivel de significância adotado (5\%), a identificação foi realizada através de letras que representam os produtos, podemos citar como exemplo a para as médias que diferiram do resultado do produto CMP5A e $a_{1}$ para o CMP21A [39].

\section{3 - RESULTADOS E DISCUSSÃO}

\section{1 - Sólidos solúveis totais - SST}

Os resultados médios obtidos de SST foram expressos em ${ }^{\circ}$ Brix e encontram-se na Tabela 1 . A análise de variância dos resultados obtidos, Tabela 2 , revela que entre os diferentes tratamentos da cenoura houve diferença significativa, sendo influenciados pelas variáveis independentes do processo: dose empregada e tempo de armazenamento. Os resultados mostram que as atmosferas utilizadas, $5 \% \mathrm{O}_{2} / 10 \% \mathrm{CO}_{2}$ e ar sintético, não acarretaram mudanças significativas entre os produtos ( $\mathrm{Ta}$ bela 2 e Figura 2). O valor de 3,4 oBrix no tempo zero para todos os produtos, quando comparado com os de LIMA et al [22], 7,98-8,48oBrix, para cenouras inteiras da variedade "Nantes", irradiadas nas mesmas doses desse trabalho, mostrou que o processamento mínimo ocasionou um decréscimo na concentração de SST, provavelmente em função das operações de descascamento, corte e lavagem, onde pode ter ocorrido perda de material hidrossolúvel.

TABELA 1. SST (oBrix) dos produtos durante o período de armazenamento.

\begin{tabular}{|c|c|c|c|c|c|c|}
\hline \multirow{2}{*}{ Produto } & \multicolumn{6}{|c|}{ Tempo de Armazenamento (dias) } \\
\hline & $\mathbf{0}$ & 4 & 8 & 12 & 16 & 20 \\
\hline CMP5A & 3,40 & 3,40 & $3,06 a^{*}$ & $3,06 \mathrm{a}$ & $2,90 \mathrm{a}$ & $2,90 \mathrm{a}$ \\
\hline CMP5B & 3,40 & 3,40 & $3,06 \mathrm{~b}$ & $3,06 \mathrm{~b}$ & $2,90 \mathrm{~b}$ & $2,90 \mathrm{~b}$ \\
\hline CMP5C & 3,40 & 3,40 & $3,06 \mathrm{c}$ & $3,06 \mathrm{c}$ & $2,90 \mathrm{c}$ & $2,90 \mathrm{c}$ \\
\hline CMP5D & 3,40 & 3,40 & $3,15 \mathrm{~d}$ & $3,15 \mathrm{~d}$ & $3,06 \mathrm{~d}$ & $3,06 \mathrm{~d}$ \\
\hline CMP5E & 3,40 & 3,40 & $3,15 \mathrm{e}$ & $3,15 \mathrm{e}$ & $3,06 \mathrm{e}$ & $3,06 \mathrm{e}$ \\
\hline CMP21A & 3,40 & 3,40 & $3,06 a_{1}$ & $3,06 a_{1}$ & $2,90 \mathrm{a}_{1}$ & $2,90 \mathrm{a}$ \\
\hline CMP21B & 3,40 & 3,40 & $3,06 b_{1}$ & $3,06 b_{1}$ & $2,90 b_{1}$ & $2,90 \mathrm{~b}$ \\
\hline CMP21C & 3,40 & 3,40 & $3,06 c_{1}$ & $3,06 c_{1}$ & $2,90 c_{1}$ & $2,90 \mathrm{c}$ \\
\hline CMP21D & 3,40 & 3,40 & $3,15 d_{1}$ & $3,15 \mathrm{~d}_{1}$ & $3,15 \mathrm{~d}_{1}$ & $3,06 \mathrm{~d}$ \\
\hline CMP21E & 3,40 & 3,40 & $3,15 \mathrm{e}_{1}$ & $3,15 \mathrm{e}_{1}$ & $3,15 \mathrm{e}_{1}$ & $3,06 \mathrm{e}$ \\
\hline
\end{tabular}

${ }^{*}$ As letras colocadas após as médias indicam que estas diferem significativamente (5\%), em cada linha, do resultado do tempo zero.

No tempo zero e quarto não houve alteração dos teores de sólidos solúveis totais para os diversos produtos, denotando que o processo de irradiação não acelerou a senescência. Resultados que estão de acordo com os de LIMA et al [22], os quais também mostraram que no tempo zero não houve diferença significativa entre os tratamentos empregados. 
TABELA 2. Análise de variância dos resultados médios de SST.

\begin{tabular}{|c|c|c|}
\hline \multicolumn{3}{|c|}{$\begin{array}{l}\text { Variáveis independentes: 1- Atmosfera; 2- Dose ; 3- Tempo } \\
\text { Variável dependente: Concentracão }\end{array}$} \\
\hline Efeito & F & $P$ \\
\hline 1 & 2,667 & 0,118115 \\
\hline 2 & $146,679 *$ & $0,000000 *$ \\
\hline 3 & $1910,235^{*}$ & $0,000000 *$ \\
\hline 12 & 1,000 & 0,430682 \\
\hline 13 & 2,667 & 0,52797 \\
\hline 23 & $20,338^{*}$ & $0,000000^{*}$ \\
\hline
\end{tabular}

*O tratamento ou a combinação dos tratamentos influencia significativamente ao nivel de $5 \%$.

Na Figura 2 observa-se, a partir do oitavo dia, o decréscimo do teor de sólidos solúveis totais com o tempo, indicativo provável do desenvolvimento de microrganismos durante o período de armazenamento, já que os açúcares presentes nos SST representam a principal fonte energética para crescimento dos mesmos, quando presentes. CARLIN et al. [7] em estudos com cenouras fatiadas encontraram redução nos valores dos açúcares, sacarose e glicose, durante o armazenamento. BAARDSETH et al. [2] também encontraram em cenouras cortadas no formato "chips" redução de $60 \%$ na concentração dos açúcares, sacarose, glicose e frutose, e atribuiram a redução ao aparecimento da fermentação nos produtos. De acordo com CHITARRA \& CARVALHO [10] as cenouras são constituídas essencialmente por açúcares livres, com predominância de sacarose sobre glicose e frutose, apresentando dessa forma ótima sensibilidade gustativa.

(A)

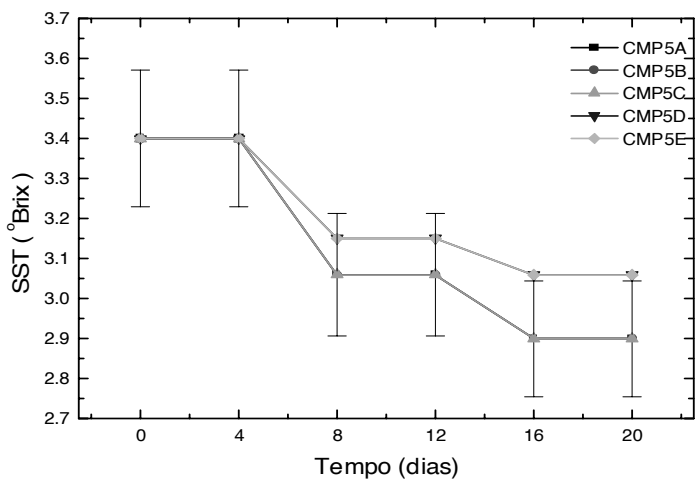

(B)

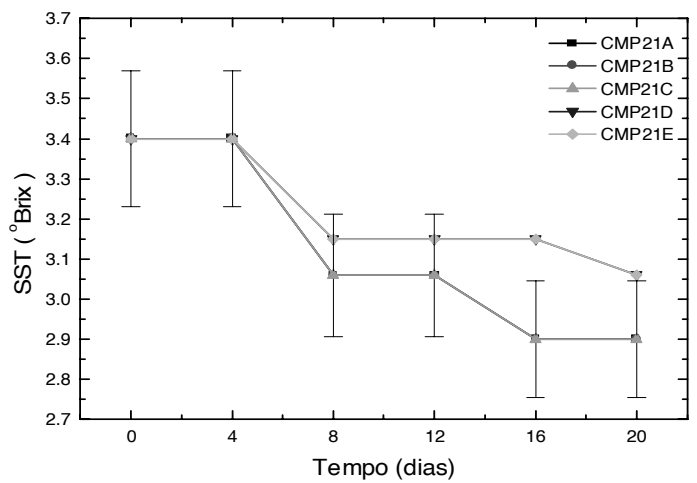

FIGURA 2. Valores médios de SST, durante o período de armazenamento, dos produtos que continham atmosfera de $5 \% \mathrm{O}_{2} / 10 \% \mathrm{CO}_{2}$ (A) e ar sintético (B).
$\mathrm{Na}$ Figura 2 observa-se ainda que os produtos CMP5D, CMP5E, CMP21D e CMP21E no $16^{\circ}$ e 20 dia diferiram em $5 \%$ dos outros produtos, mostrando redução na taxa de decréscimo da concentração de SST, destacando provável efeito protetor das doses de 0,75 e $1,00 \mathrm{kGy}$, independente da atmosfera empregada.

\section{2 - Acidez total titulável - ATT}

De acordo com WILEY [41] os ácidos orgânicos predominantes em cenouras são principalmente o ácido málico, o cítrico, o isocítrico, o succínico e o fumárico. Os resultados médios obtidos para acidez das cenouras encontramse na Tabela 3, enquanto que a sua análise de variância na Tabela 4. As variáveis independentes que influenciaram significativamente os produtos foram as doses empregadas e o tempo de armazenamento.

Os resultados mostram que as atmosferas utilizadas, $5 \% \mathrm{O}_{2} / 10 \% \mathrm{CO}_{2}$ e ar sintético, não acarretaram mudanças significativas entre os produtos (Tabela 4 e Figura 3), pois as concentrações encontradas para uma mesma dose empregada, ao longo do tempo, ficaram próximas. Os resultados médios de acidez no tempo zero para os diversos produtos são semelhantes aos obtidos por LIMA et al. [22] para cenouras da mesma variedade, inteiras e irradiadas com as mesmas doses deste trabalho.

TABELA 3. ATT (\% ácido cítrico) dos produtos durante o período de armazenamento.

\begin{tabular}{|c|c|c|c|c|c|c|}
\hline \multirow{2}{*}{ Produto } & \multicolumn{6}{|c|}{ Tempo de Armazenamento (dias) } \\
\hline & $\mathbf{0}$ & 4 & 8 & 12 & 16 & 20 \\
\hline CMP5A & 0,64 & 0,53 & 0,54 & 0,73 & $1,00 \mathrm{a}^{*}$ & $1,30 \mathrm{a}$ \\
\hline CMPSB & 0,61 & 0,46 & 0,48 & 0,61 & $0,91 \mathrm{~b}$ & $0,95 \mathrm{~b}$ \\
\hline CMP5C & 0,60 & 0,46 & 0,47 & 0,53 & 0,70 & 0,74 \\
\hline CMP5D & 0,61 & 0,46 & 0,47 & 0,52 & 0,50 & 0,50 \\
\hline CMPSE & 0,59 & 0,50 & 0,50 & 0,51 & 0,51 & 0,50 \\
\hline CMP21A & 0,64 & 0,56 & 0,53 & 0,78 & $1,00 a_{1}$ & $1,00 a_{1}$ \\
\hline CMP21B & 0,61 & 0,51 & 0,53 & 0,64 & $0,90 b_{1}$ & $0,92 b_{1}$ \\
\hline CMP21C & 0,62 & 0,50 & 0,51 & 0,51 & 0,70 & 0,75 \\
\hline CMP21D & 0,62 & 0,50 & 0,52 & 0,48 & 0,50 & 0,50 \\
\hline CMP21E & 0,62 & 0,50 & 0,50 & 0,48 & 0,50 & 0,53 \\
\hline
\end{tabular}

${ }^{*}$ As letras colocadas após as médias indicam que estas diferem significativamente $(5 \%)$, em cada linha, do resultado do tempo zero.

TABELA 4. Análise de variância dos resultados médios de ATT.

\begin{tabular}{|c|c|c|}
\hline \multicolumn{3}{|c|}{$\begin{array}{l}\text { Variáveis independen tes: 1- Atmosfera; 2- Dose ; 3- Tempo } \\
\text { Variável dependente: Concentração }\end{array}$} \\
\hline Efeito & F & $\mathbf{P}$ \\
\hline 1 & 0,03115 & 0,861681 \\
\hline 2 & $73,24003^{*}$ & 0,000000 * \\
\hline 3 & $64,63754 *$ & $0,000000^{*}$ \\
\hline 12 & 0,64333 & 0,637903 \\
\hline 13 & 1,39759 & 0,267533 \\
\hline 23 & $15,05763^{*}$ & $0,000000 *$ \\
\hline
\end{tabular}

${ }^{*} \mathrm{O}$ tratamento ou a combinação dos tratamentos influencia significativamente ao nivel de $5 \%$.

Observa-se que no quarto e oitavo dia de armazenamento para todos os produtos houve um decréscimo no teor de ATT, Figura 3, mostrando aumento da oxidação dos ácidos orgânicos presentes nas cenouras minimamente processadas, causada possivelmente por uma maior taxa de respiração pelo aumento da superficie exposta das cenouras. A partir do $12^{\circ}$ dia ocorreu um aumento na concentração de ácidos orgânicos para os produtos controles e irradiados nas doses de 0,25 e 
0,50kGy, sendo que essa taxa decresce com o aumento da dose empregada, confirmando os resultados de SST. De acordo com KAKIOMENOU, TASSOU \& NYCHAS [19] em cenouras fatiadas armazenadas durante 17 dias a $10^{\circ} \mathrm{C}$ ocorreu aumento da acidez atribuida pela produção dos ácidos lático, acético, málico, succínico e pirúvico, podendo ser creditado como um produto do metabolismo microbiano. Nos produtos irradiados nas doses de 0,75 e 1,00kGy os resultados de ATT se mantiveram praticamente constantes entre o quarto e último dia de análise, mostrando uma possivel estabilidade microbiológica. CARLIN et al. [7] encontraram aumento da acidez em cenouras fatiadas "prontas para o consumo", com a produção dos ácidos acético e lático. De acordo com HAGENMAIER \& BAKER [14] em estudos com cenouras fatiadas tratadas com irradiação ionizante gama na dose de 0,45kGy também ocorreram aumento da acidez com a produção de ácido acético.

(A)

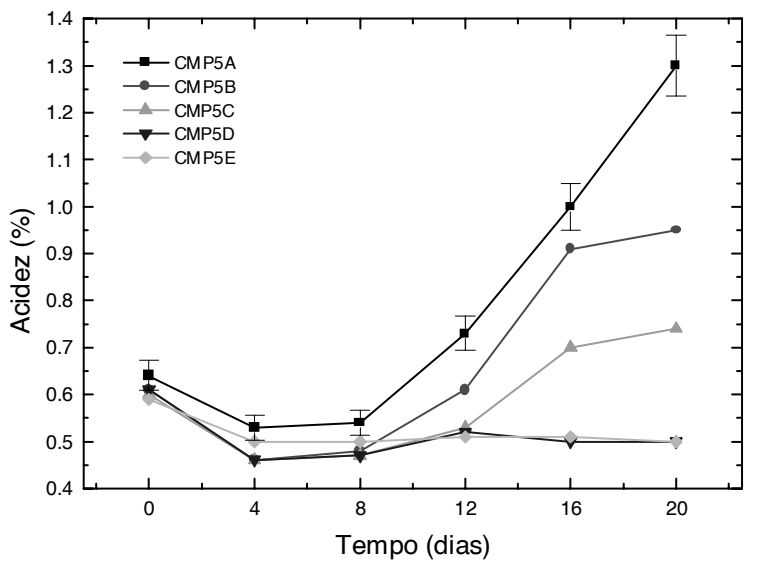

(B)

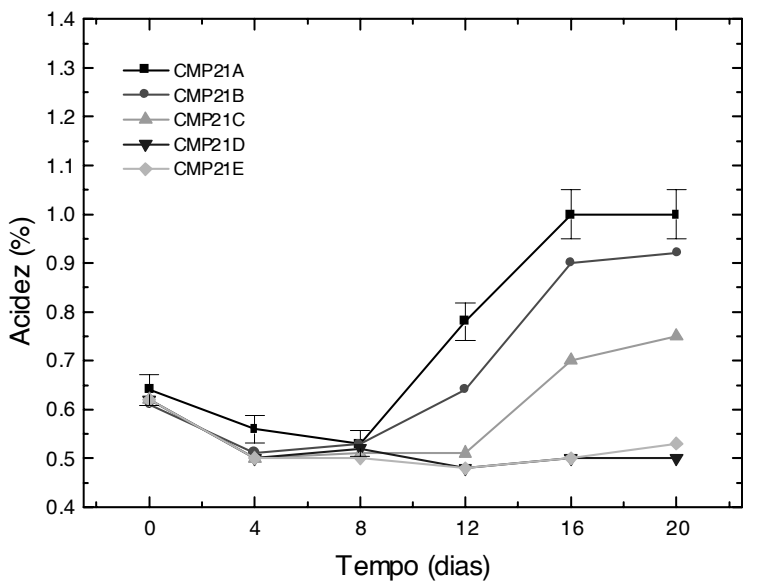

FIGURA 3. Valores médios de ATT (\% ácido cítrico), durante o período de armazenamento, dos produtos que contêm atmosfera de $5 \% \mathrm{O}_{2} / 10 \% \mathrm{CO}_{2}$ (A) e ar sintético (B).

\section{$3.3-\mathbf{p H}$}

Os valores médios de $\mathrm{pH}$ dos diferentes tratamentos da cenoura pela irradiação estão apresentados na Tabela 5. $\mathrm{O} \mathrm{pH}$ é um fator intrínseco ao alimento e exerce o maior efeito seletivo sobre a microflora apta a se desenvolver [21].

Os valores encontrados para o $\mathrm{pH}$, entre os diferentes tratamentos, mostraram que as variáveis independentes do processo, dose de irradiação e tempo de armazenamento, influenciaram significativamente os valores de $\mathrm{pH}$ e que as atmosferas empregadas não influenciaram significativamente, Tabela 6. No tempo zero, todos os resultados de $\mathrm{pH}$ estiveram dentro de um erro de $5 \%$, quando relacionados com o padrão, que eram os produtos controles.

TABELA 5. $\mathrm{pH}$ dos produtos durante o período de armazenamento.

\begin{tabular}{|c|c|c|c|c|c|c|}
\hline \multirow{2}{*}{ Produto } & \multicolumn{6}{|c|}{ Tempo de Armazenamento (dias) } \\
\hline & $\mathbf{0}$ & 4 & 8 & 12 & 16 & 20 \\
\hline CMP5A & 6,82 & 6,88 & 6,32 & $6,17 \mathrm{a}^{*}$ & $5,10 \mathrm{a}$ & $5,05 \mathrm{a}$ \\
\hline CMPSB & 6,72 & 6,49 & 6,17 & $6,07 \mathrm{~b}$ & $5,38 \mathrm{~b}$ & $5,08 \mathrm{~b}$ \\
\hline CMP5C & 6,68 & 6,55 & 6,50 & $5,51 \mathrm{c}$ & $5,23 \mathrm{c}$ & $5,21 \mathrm{c}$ \\
\hline CMPSD & 6,67 & 6,42 & 6,29 & $6,17 \mathrm{~d}$ & $5,98 \mathrm{~d}$ & $5,70 \mathrm{~d}$ \\
\hline CMP5E & 6,62 & 6,12 & 6,25 & $5,94 \mathrm{e}$ & $5,54 \mathrm{e}$ & $5,57 \mathrm{e}$ \\
\hline CMP21A & 6,84 & 6,83 & 6,55 & $6,17 \mathrm{a}_{1}$ & $5,49 a_{1}$ & $5,17 a_{1}$ \\
\hline CMP21B & 6,78 & 6,72 & 6,52 & $5,27 \mathrm{~b}_{1}$ & $4,83 b_{1}$ & $4,90 b_{1}$ \\
\hline CMP21C & 6,62 & 6,28 & 6,23 & $5,71 \mathrm{c}_{1}$ & $5,52 \mathrm{c}_{1}$ & $4,97 \mathrm{c}_{1}$ \\
\hline CMP21D & 6,58 & 6,53 & 6,46 & 6,38 & $5,67 d_{1}$ & $5,57 \mathrm{~d}_{1}$ \\
\hline CMP21E & 6,50 & 6,48 & 6,47 & 6,40 & $5,30 \mathrm{e}_{1}$ & $5,22 \mathrm{e}_{1}$ \\
\hline
\end{tabular}

*As letras colocadas após as médias indicam que estas diferem significativamente (5\%), em cada linha, do resultado do tempo zero.

Os valores de $\mathrm{pH}$ das cenouras minimamente processadas encontram-se na faixa de 6,50 a 6,84 e foram semelhantes aos apresentados por ODUMERU et al. [26].

TABELA 6. Análise de variância dos resultados médios de pH.

Variáveis independentes: 1- Atmosfera; 2- Dose; 3- Tempo

Varível dependente: Concentracão

$\begin{array}{ccc}\text { Efeito } & \mathbf{F} & \mathbf{P} \\ \mathbf{1} & 0,01967 & 0,889877 \\ \mathbf{2} & 3,90437^{*} & 0,016782^{*} \\ \mathbf{3} & 74,08254^{*} & 0,000000^{*} \\ \mathbf{1 2} & 0,64771 & 0,635005 \\ \mathbf{1 3} & 0,59432 & 0,704568 \\ \mathbf{2 3} & 1,64584 & 0,136813\end{array}$

*O tratamento ou a combinação dos tratamentos influencia significativamente ao nivel de $5 \%$.

Ao longo do armazenamento pode ser notado um decréscimo nos valores de $\mathrm{pH}$, indicando que o provável aumento dos ions $\mathrm{H}^{+}$teve como origem a produção de ácidos orgânicos provenientes da ação de microrganismos. BAARDSETH et al [2] em estudos com cenouras cortadas no formato "chips" também encontraram redução nos valores de $\mathrm{pH}$. KAKIOMENOU, TASSOU \& NYCHAS [19] em estudos microbiológicos com cenouras fatiadas armazenadas durante 17 dias a $10^{\circ} \mathrm{C}$ também encontraram redução nos valores de $\mathrm{pH}$ e atribuiram a redução, ao aumento da produção dos ácidos lático, acético e málico, entre outros, por Bactérias lácticas. Os produtos CMP5D, CMP5E e CMP21D, Figuras 4A e B, no 20 dia de armazenamento, diferiram significativamente $(\mathrm{p}<0,05)$ dos outros, mostrando possivel efeito conservador das doses de 0,75 e 1,00kGy, além da estabilidade microbiológica dos produtos. 
(A)

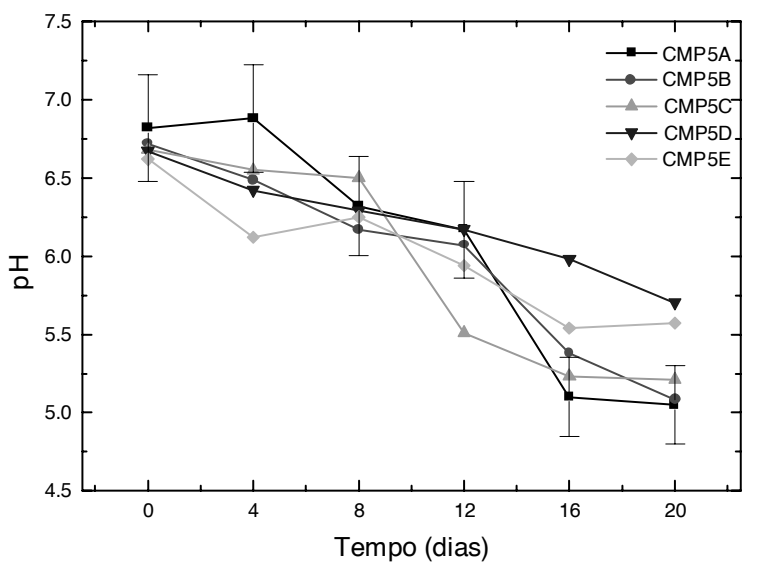

(B)

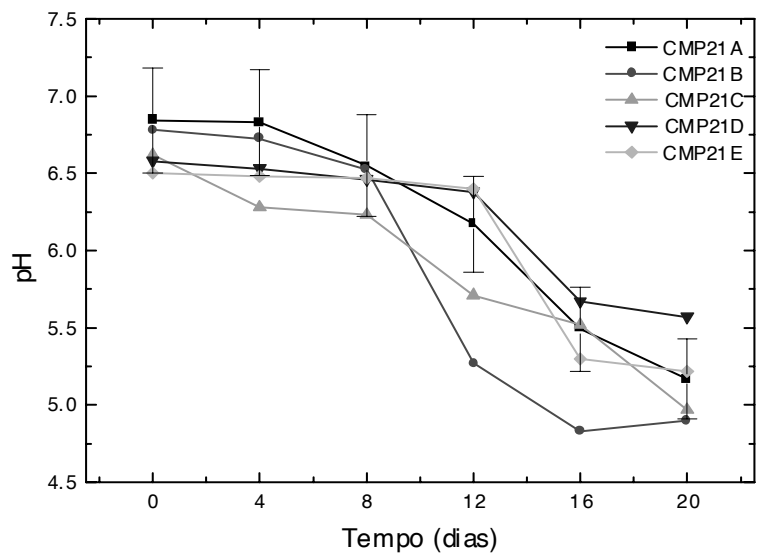

FIGURA 4. Valores médios de pH, durante o período de armazenamento, dos produtos que contêm atmosfera de $5 \% \mathrm{O}_{2} / 10 \% \mathrm{CO}_{2}$ (A) e ar sintético (B).

\section{4 - Avaliação microbiológica}

O Regulamento Técnico sobre Padrões Microbiológicos para Alimentos (2001) da Agência Nacional de Vigilância Sanitária (ANVISA) estabelece para hortaliças, legumes e similares frescos, in natura, preparados (descascados, selecionados ou fracionados), sanificados, refrigerados ou congelados, para consumo direto, devam ser realizadas as análises microbiológicas de Coliformes a $45^{\circ} \mathrm{C} / \mathrm{g}$ e Salmonella sp., tendo a tolerância de $10^{2} \mathrm{NMP} /$ $\mathrm{g}$ e ausência em 25g, respectivamente. No item 22 Pratos Prontos para o Consumo a Base de Verduras, Legumes, Raizes, Tubérculos e Similares do Regulamento, além das análises citadas acima, estabelece que deverão ser realizados também as determinações de Bacillus cereus, Staphilococus coagulase positivo, tendo por tolerância $10^{3} \mathrm{UFC} / \mathrm{g}$ para ambos.

A contagem padrão de bactérias aeróbias mesófilas (PCA) realizada nesse estudo teve por finalidade servir como indicador de qualidade higiênica dos produtos, fornecendo também uma idéia do tempo de vida útil de armazenamento. Sua presença em grande número de- monstra contaminação excessiva das matérias-primas; lavagem e desinfecção mal realizadas; higiene inadequada na produção; e uso de tempo/temperatura impróprios durante a produção ou conservação dos produtos, ou uma combinação destas circunstâncias [26, 36]. A contagem de mesófilos acima de $10^{7}-10^{8} \mathrm{UFC} / \mathrm{g}$ indica término da vida útil dos produtos [3].

Durante o periodo de armazenamento, para todos grupos pesquisados, não foram detectadas as presenças de Coliformes Totais e E. coli (NMP < 0,3/g) até o 24ㅇdia. Também, não foram detectados os patógenos $B$. cereus e Staphilococus coagulase positivos em $0,1 \mathrm{~g}$ dos produtos. As contagens de Bactérias Lácticas mantiveram-se menor que $100 \mathrm{UFC} / \mathrm{g}$ durante o período analisado para todos os produtos.

Nas Figuras $5 A$, $B$ e $6 A$ observa-se que os produtos CMP5A, CMP5B e CMP21A, após o 8 dia de armazenamento, apresentaram $\mathrm{CTM}>1 \times 10^{6}$, limite máximo estabelecido para a vida útil desse tipo de produto, sendo que a partir do $12 \circ$ dia já apresentavam evidentes sinais de deterioração como limosidade e exudação. Os produtos CMP5E, CMP21B, CMP21C e CMP21E ultrapassaram o limite máximo de CTM no 20 dia de análise, Figuras $5 E$ e $6 B, C$ e $E$, respectivamente. Porém somente os produtos CMP5C, CMP5D e CMP21D ultrapassaram o 20 o dia com CTM $<1 \times 10^{6}$, mas o processo que associou a dose de irradiação de $0,75 \mathrm{kGy}$ e a atmosfera modificada de $5 \% \mathrm{O}_{2} / 10 \% \mathrm{CO}_{2}$ com o processamento mínimo das cenouras (CMP5D) conseguiu atingir o $24^{\circ}$ dia de forma própria para o consumo.

Os produtos, que além de sofrerem lavagem e desinfecção, foram submetidos a irradiação nas doses de 0,5, 0,75, e 1,00kGy, independente da atmosfera introduzida no espaço-livre das embalagens, tiveram redução da ordem de 3 a 4 ciclos logaritmicos na contagem total de mesófilos no tempo zero de armazenamento, quando comparados com os controles. De acordo com NGUYEN-THE \& CARLIN [25], CHERVIN \& BOISSEAU [9] e BRACKETT [5] para cenouras comercializadas frescas e cortadas, as quais foram somente lavadas e desinfectadas com cloro, apresentaram uma contagem inicial de mesófilos da ordem de $10^{6} \mathrm{UFC} / \mathrm{g}$. HAGENMAIER e BAKER [14] em estudos com cenouras fatiadas observaram uma redução na contagem de mesófilos entre a amostra controle, que foi somente submetida as operações de lavagem e desinfecção, e a irradiada na dose de 0,45kGy de $13.000 U F C / g$ para $200 \mathrm{UFC} / \mathrm{g}$, respectivamente.

MOSSEL et al. [24] reportaram que microrganismos gram-negativos são mais sensiveis a irradiação do que outros tipos, mais a possibilidade de anaerobiose em embalagens seladas e a diminuição de competidores pela radiação $\gamma$ podem favorecer o crescimento de patógenos. De acordo com BARRY-RYAN \& O'BEIRNE [3] o descascamento e corte empregados em cenouras minimamente processadas podem provocar um aumento na taxa de respiração, em função da superficie exposta. Sendo assim, optou-se pelo emprego de uma atmosfera modificada com teor inicial de $5 \%$ de $\mathrm{O}_{2}$ e uma alta permeabilidade da embalagem a esse gás. 
(A)

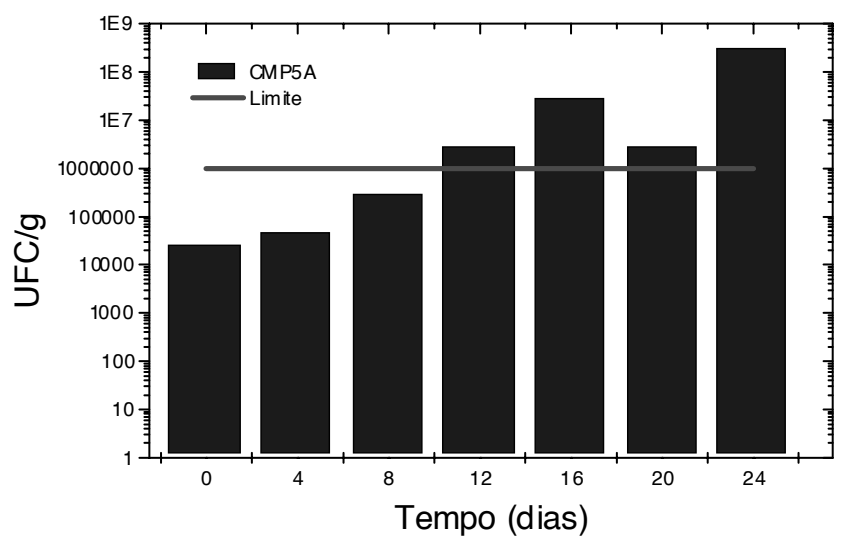

(C)

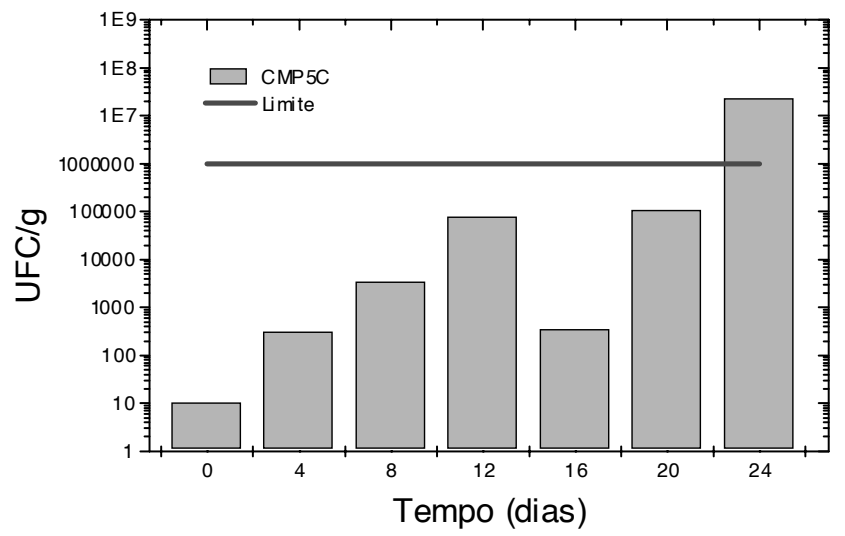

(E)

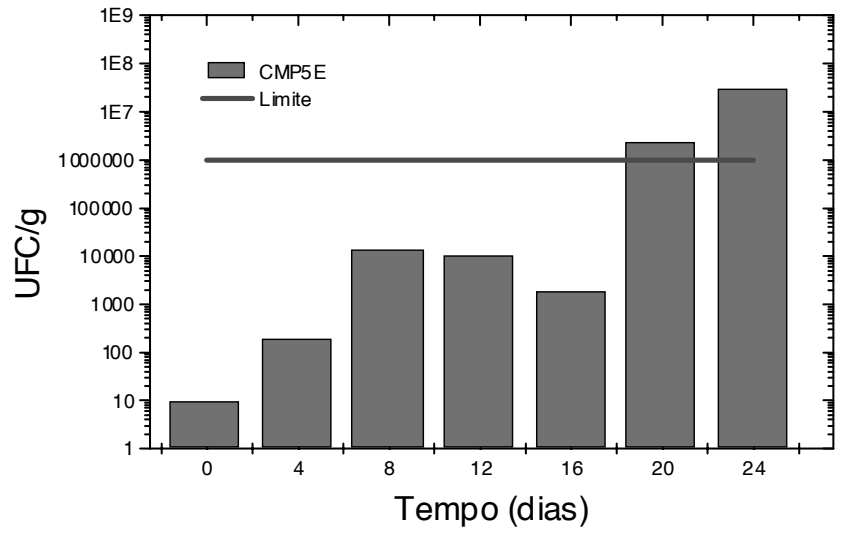

(B)

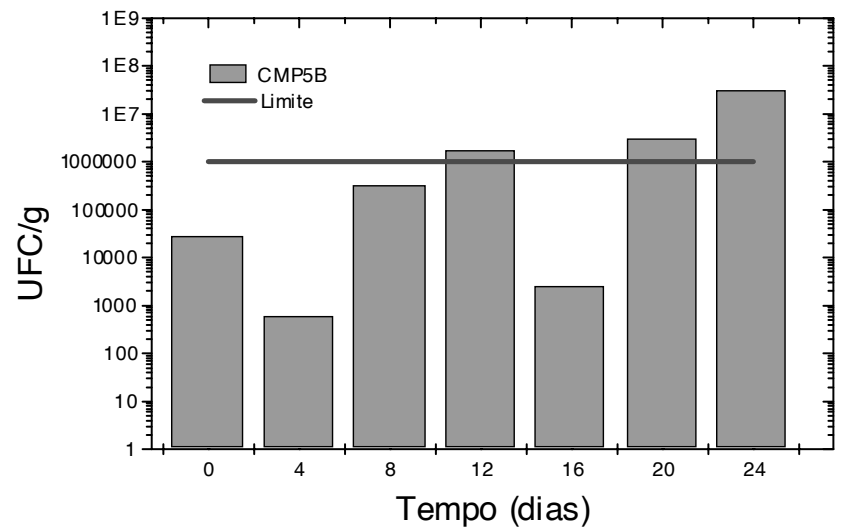

(D)
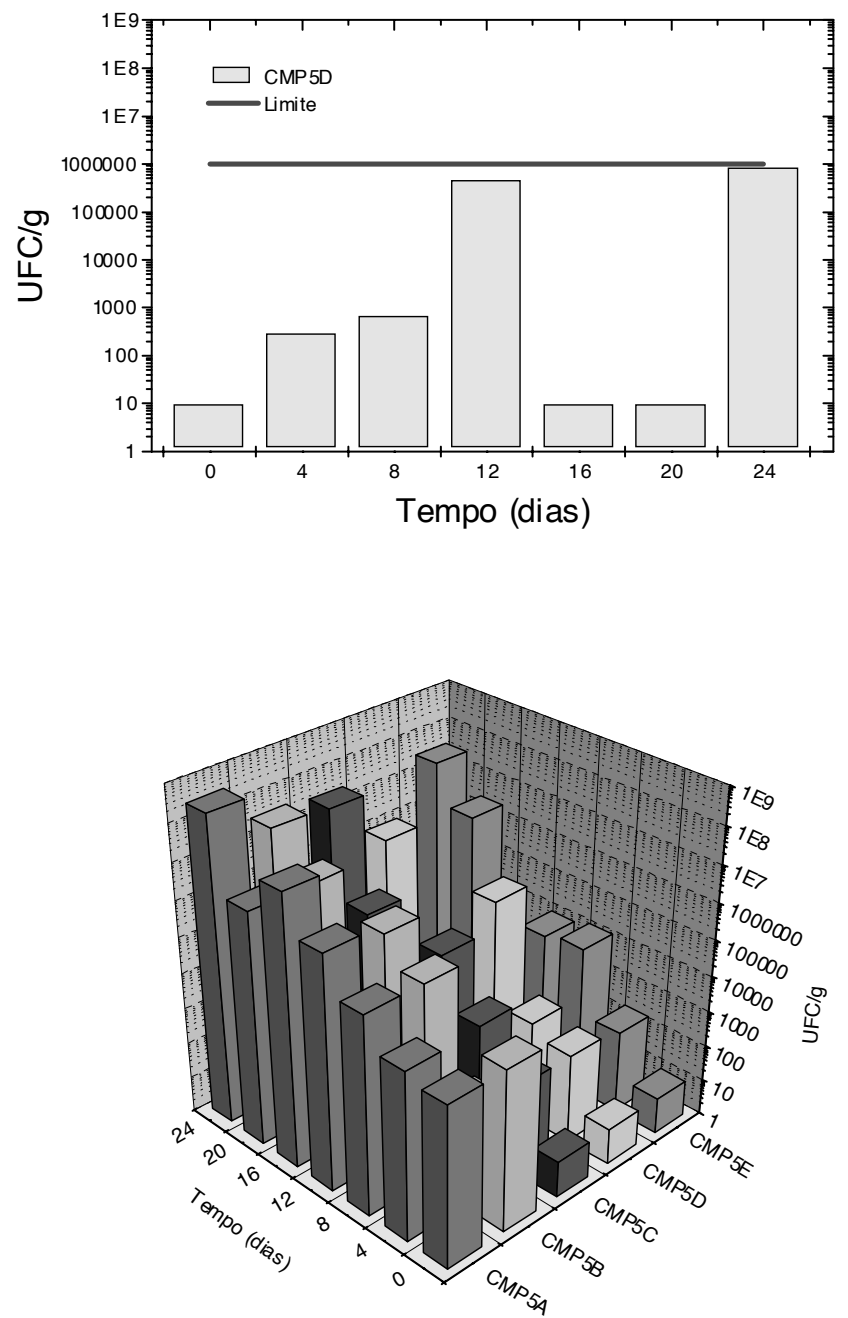

FIGURA 5. Contagem total de mesófilos, durante o período de armazenamento, dos produtos: CMP5A (A), CMP5B (B), CMP5C (C), CMP5D (D) e CMP5E (E). 
(A)

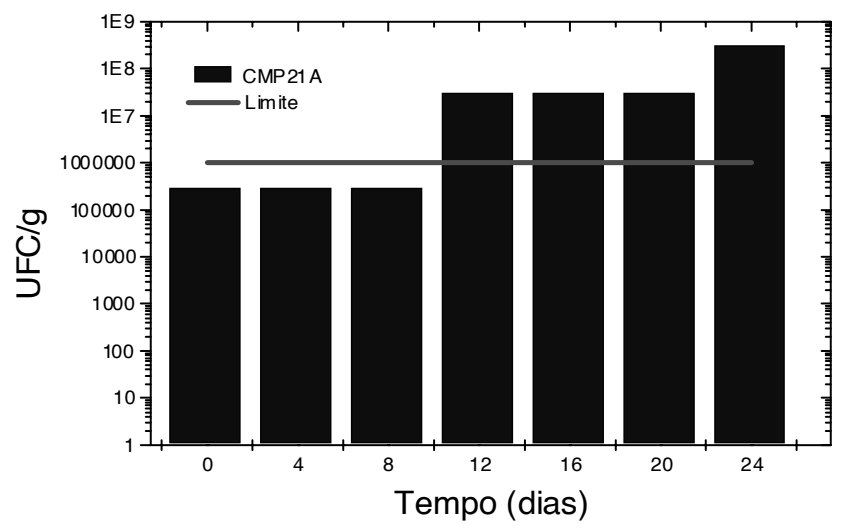

(C)

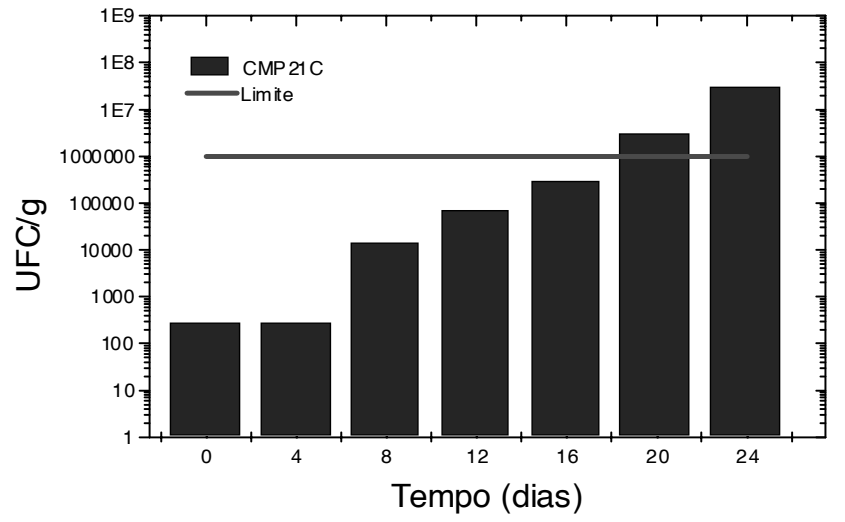

(E)

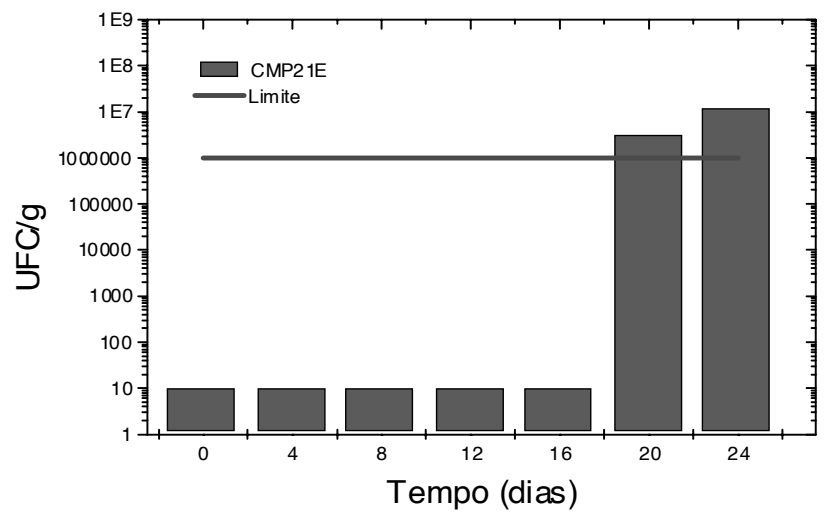

(B)

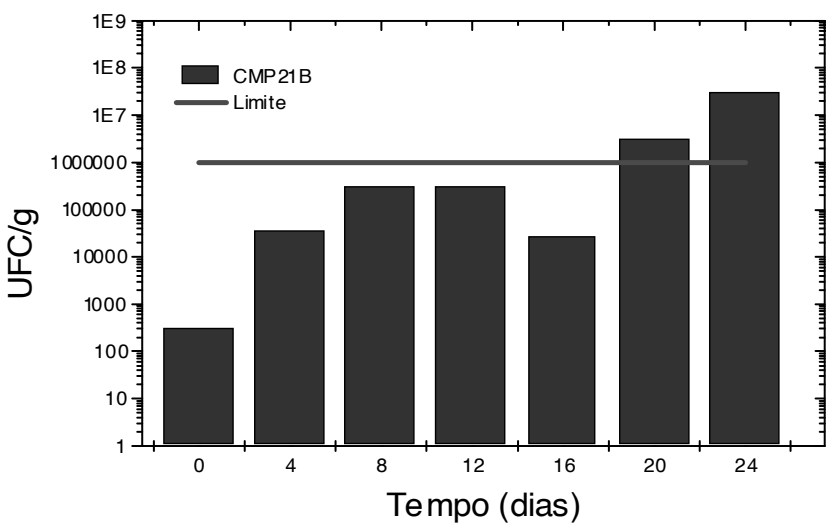

(D)
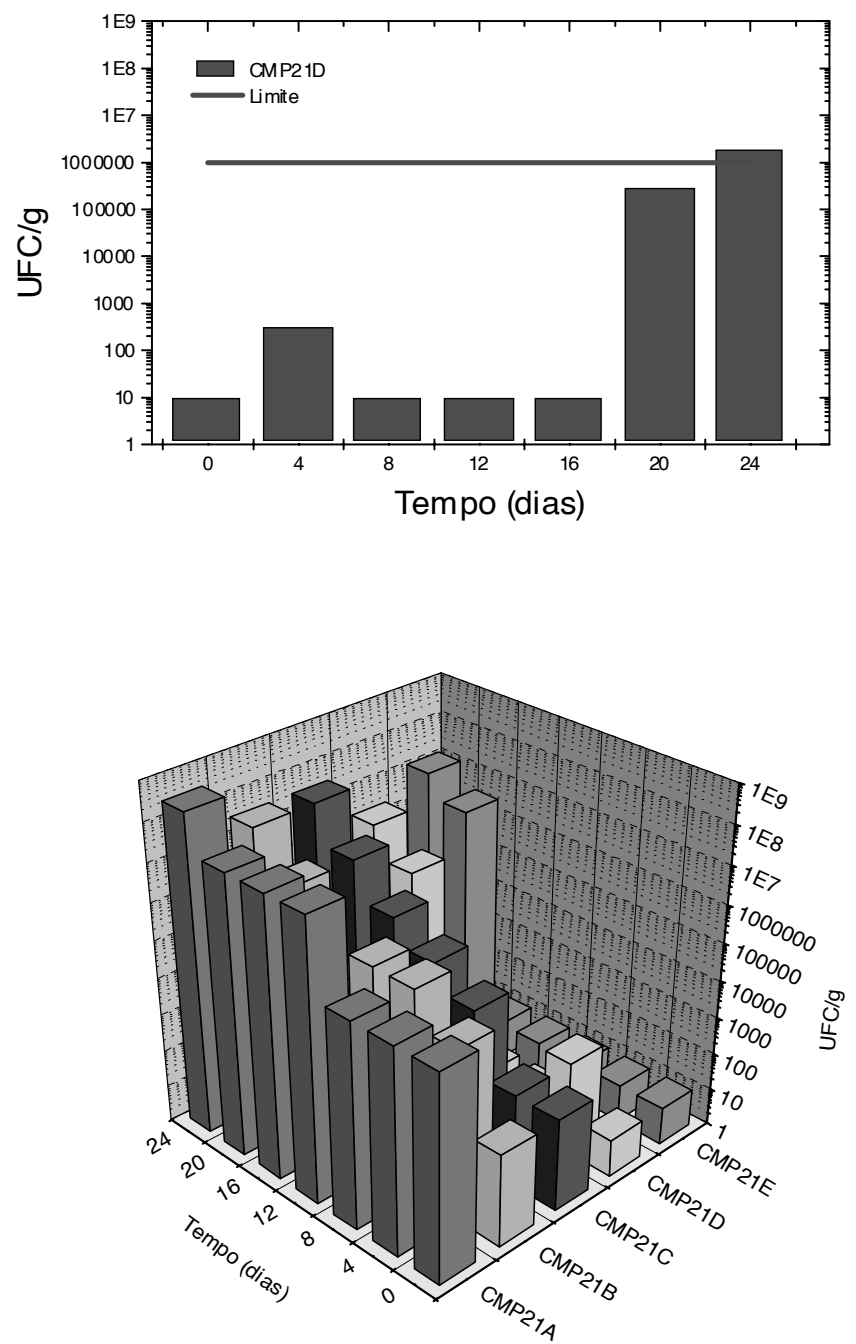

FIGURA 6. Contagem total de mesófilos, durante o período de armazenamento, dos produtos: CMP2 1A (A), CMP2 1B (B), CMP2 1C (C), CMP21D (D) e CMP21E (E). 
Durante o periodo de armazenamento dos diversos produtos não foram detectadas as presenças de bactérias lácticas, mostrando que não foi atingido o estado de anaerobiose em nenhuma das embalagens. Resultados semelhantes foram encontrados por SODE e KÜHN [37], que trabalhando com cenouras cortadas em filetes de $4,5 \mathrm{~mm}$ de comprimento e acondicionadas em embalagens com permeabilidade variando en$\mathrm{t}$ $r$

\section{$\mathrm{e}$} 1020-1250 $\mathrm{cm}^{3} \mathrm{O}_{2} /\left(\right.$ dia.Bar. $\left.\mathrm{m}^{2}\right)$, concluiram que a associação de baixo conteúdo inicial de oxigênio (5-7\%) com a alta permeabilidade das embalagens podem estabilizar a concentração de oxigênio no interior dos sacos. CARLIN et al. [8] obtiveram, de forma análoga, uma concentração estável de oxigênio partindo de aproximadamente $4 \%$ e de embalagens com permeabilidade de $950 \mathrm{~mL} \mathrm{O}_{2}$ / (dia.Bar. $\mathrm{m}^{2}$ ). Muitos fatores além da atmosfera no interior das embalagens, também, podem afetar a respiração, em termos de taxa e balanço entre o consumo de $\mathrm{O}_{2}$ e a produção de $\mathrm{CO}_{2}$, entre eles podemos citar a cultivar, fatores de crescimento, estado de maturação, o tipo de corte aplicado e o manuseio [1].

\section{4 - CONCLUSÕES}

As cenouras minimamente processadas que foram submetidas a irradiação nas doses de 0,5, 0,75 e $1,00 k G y$, além da lavagem e desinfecção, apresentaram redução da ordem de 3 a 4 ciclos logarítmicos na contagem total de mesófilos (CTM), no tempo zero de armazenamento.

A irradiação ionizante gama em cenouras minimamente processadas foi eficiente, sendo que a dose de $0,75 \mathrm{kGy}$ e atmosfera modificada com 5\% $\mathrm{O}_{21} 10 \% \mathrm{CO}_{2}$ (CMP5D) foram as condições de processo mais indicadas, por terem mantido o produto em condições aceitáveis para o consumo durante 24 dias de armazenamento à $5^{\circ} \mathrm{C}$, proporcionando um aumento na vida útil do produto de aproximadamente 3 vezes em relação ao controle (não irradiado).

\section{5 - REFERÊNCIAS}

[1] AHVENAINEN, R. New approaches in improving shelf life of minimally processed fruit and vegetables. Trends in Food Science \& Technology, v.7, 1996.

[2] BAARDSETH,P.; ROSENFELD, H. J.; SUNDT, T. W.; SKREDE, G.; LEA, P. \& SLINDE, E. Evaluation of carrot varieties for production of deep-fried carrot chips - I. Chemical aspects. Food Research International, v. 28, n. 3, p. 195-200, 1995.

[3] BARRY-RYAN, C. \& O'BEIRNE, D. Effects of peeling methods on the quality of ready-to-use carrot slices. International Journal of Food Science and Technology, v. 35, n. 2, p. 243-254, 2000.

[4] BARUFFALDI, R. \& OLIVEIRA, M. N. Fundamentos de Tecnologia de Alimentos, v. 3, Rio de Janeiro: Atheneu, 1998. $317 \mathrm{p}$.

[5] BRACKETT, R. E. Microbiological spoilage and pathogens in minimally processed refrigerated fruits and vegetables.
In: WILEY, R. C. Minimally Processed Refrigerated Fruits and Vegetables. New York: Chapman \& Hall, p. 269-312, 1994.

[6] BRADFORD, R \& LOAHARANV, P. A Harmonized Approach to Regulating Food Irradiation Based on Groups of Foods. WHO/IAEA/FAO. In: Seminar on harmonization of regulations on food irradiation in Asia and the Pacific. Malaysia, IAEA -TECDOC - 696, p. 155-160, 1993.

[7] CARLIN, F.; NGUYEN-THE, C.; CHAMBROY, Y. \& REICH, M. Effects of controlled atmospheres on microbial spoilage, electrolyte leakage and sugar content of fresh "ready to use" grated carrots. International Journal of Food Science and Technology, v.25, p. 110-119, 1990 a.

[8] CARlin, F.; NGUYen-THE, C., HilbeRT, G. \& CHAMBROY, Y. Modified atmosphere packaging of fresh "ready-to-use" grated carrots in polymeric films. Journal of Food Science, v. 55, n. 4, p. 1033-1038, $1990 \mathrm{~b}$.

[9] CHERVIN, C. \& BOIsseaU, P. Quality Maintenance of "ready-to-eat"shredded carrots by gamma irradiation. Journal of Food Science, v. 59, n. 2, p. 359$361,1994$.

[10] CHITARRA, M. I. F \& CARVALHO, V. D. Cenoura: Qualidade e Industrialização. Informe Agropecuário, v. 10, n. 120, 1984.

[11] DIEHL, J. F. Safety of Irradiated Foods. New York: Marcel Dekker, Inc., 1990. 345p.

[12] FDA. Section 179.26: Ionizing radiation for the treatment of food. In: Code of Federal Regulations: Food and Drugs, Title 21, p.389-390.U.S.Gov. Printing Office, Washington, D.C., 1995.

[13] FLOROS, J. D. The shelf life of fruits and vegetables. In: Shelf life studies of foods and beverages. London: Elsevier Science Publishers B. V., p. 195-2 16, 1993.

[14] HAgenmaier, R. D. \& BAKER, R. A. Microbial population of shredded carrot in modified atmosphere packaging as related to irradiation treatment. Journal of Food Science, v.63, n.1, p.162-164, 1998.

[15] HARRIGAN, W. F. Laboratory Methods in Food Microbiology. $3^{\text {a }}$ ed. London: Academic Press, 1998. $532 \mathrm{p}$.

[16] HERNER, R. H. \& KRAHN, T. R. Chopped lettuce should be kept dry and cold. In: WILEY, R. C. Frutas y hortalizas minimamente procesadas y refrigeradas. España: Ed. Acribia, S.A., 1997, 362p.

[17] INSTITUTO ADOLFO LUTZ (IAL). Normas analíticas do Instituto Adolfo Lutz, $3^{\text {a }}$ ed., v.1, São Paulo, 1985. $533 \mathrm{p}$.

[18] KADER, A. A. Potential applications of ionizing radiation in postharvest handling of fresh fruits and vegetables. Food Technology, v. 40, n. 6, p. 117 $121,1986$.

[19] KAKIOMENOU, K. TASsoU, C. \& NYCHAS, G. J. Microbiological, physicochemical and organoleptic changes of shredded carrots stored under modified storage. International Journal of Food Science and Technology, v. 31, p. 353-358, 1996.

[20] KILCAST, D. Effect of irradiation on vitamins. Food Chemistry, v. 49, p. 157-164, 1994.

[21] LEITÃO, M. F. F. Microbiologia de sucos, polpas e produtos ácidos. In: Industrialização de Frutas. Manual Técnico, n. 8. Campinas: ITAL, p. 33-52, 1991. 206 p.

[22] LIMA, K. S. C.; GROSSI, J. L. S.; LIMA, A. L. S.; ALVES, P. 
F. M. P.; CONEGLIAN, R. C. C.; GODOY, R. L. O. \& SABAA-SRUR, A. U. Efeito da irradiação ionizante g na qualidade pós-colheita de cenouras (Daucus carota L.) cv. Nantes. Ciênc. Tecnol. Aliment., Campinas, v. 21, n. 2, p. 202-208, 2001.

[23] MATIN, M. A., BHUIYA, A. D., AMIN, M. R. \& MALEK, M. A. Irradiation of onions, pulses and dried fish: process control, storage, test marketing and economic analysis of the process. IAEA - TEC DOC 871, Vienna, Áustria, p. 19-49, 1996.

[24] MOSSEl, D. A. A.; CORRY, J. E. L.; STRUIJK, C. B. \& BAIRD, R. M. Essentials of the microbiology of foods. New York: John Wiley \& Sons, Inc., 1995.

[25] NGUYEN-THE, C. \& CARLIN, F. The microbiology of minimally processed fresh fruits and vegetables. Critical Reviews Food Science Nutrition, v. 34, n. 4, p. 371 401, 1994.

[26] ODUMERU, J. A.; MITICHELL, S. J.; ALVES, D. M.; LYNCH, J. A.; YEE, A. J.; WANG, S. L.; STYLIADIS, S. \& FARBER, J. M. Assessment of the microbiological quality of readyto-use vegetables for healt-care food services. Journal of Food Protection, v. 60, n. 8, p. 954-960, 1997.

[27] ORGANIZAÇÃO MUNDIAL DA SAÚdE (OMS). Wholesomeness of Irradiated Food: (TRS 659). World Health Organization, Geneva, Switzerland, 1981.

[28] _. Nutricion y prevención de enfermedades crónicas. Informe Técnico 797, Genebra, 1990. 223p.

[29] . Inocuidad e idoneidad nutricional de los alimentos irradiados. Genebra, 1995. 172p.

[30] PÁDUA, J. G.; PINTO, C. M. F. \& CASALI, V. W. D. Cultiva- res de Cenoura. Informe Agropecuário, v. 10, n. 120, 1984.

[31] POF - Pesquisa de Orçamentos Familiares 1987/88. Consumo Alimentar Domiciliar "Per Capita". n.2. IBGE.CDDI, Rio de Janeiro, 1991. 70p.

[32] REYES, V. G. Improved preservation systems for minimally processed vegetables. Food Australia, v. 48, n. 2, p. 87-90, 1996.

[33] RIQUELME, F.; PRETEL, M. T.; MARTÍNEZ, G.; SERRANO, M.; AMORÓS, A. \& ROMOJARO, F. Packaging of fruits and vegetables: recent results. In: MATHLOUTHI, M. Food packaging and preeservation. London: Blackie Academic \& Professional, p. 141158, 1994

[34] SABAA-SRUR, A. U. O.; BRECHT, J. K.; SARGENT, S. A. \& BARTZ, J. A. Recommended chlorine levels for treatment of float-tank water in tomato packinghouses. In: Internacional Symposium, DavisCalifórnia, Annales of Posthavest, 1992.

[35] SHEWFELT, R. L. Quality of minimally processed fruits and vegetables. Journal of Food Quality, v. 10, p. 143156, 1987.

[36] SIQUEIRA, R. S. Manual de microbiologia de alimentos. Centro Nacional de Pesquisa de Tecnologia Agroindustrial de Alimentos (CTAA). Rio de Janeiro: EMBRAPA, 1995. $159 \mathrm{p}$.

[37] SODE, F. \& KÜHN, B. F. Respiration in MA-packed, cut carrots. London: Elsevier Science Limited, p. 223-232, 1998.

[38] TATCHER, F. S. \& CLARK, D. S. Analisis microbiológicas de los alimentos. España: Ed. Acribia, p. 70-169, 1973.

[39] VIEIRA, S. Introdução à Bioestatística. 6 ${ }^{\text {a }}$ ed. Rio de Janeiro: Campos, 1989. 294 p.

[40] WHITE, G.C. Handbook of chlorination. For potable water, wastewater, cooling water, industrial processes and swimming pools. Van Nostrand Reinhold Company, New York, p. 215-223, 1972

[41] WILEY, R. C. Frutas y hortalizas mínimamente procesadas y refrigeradas. España: Ed. Acribia, S.A., 1997, 362p.. 